\title{
Tensions in setting health care priorities for South Africa's children
}

Willem A Landman and Lesley D Henley East Carolina University, Greenville, North Carolina, USA, and Red Cross War Memorial Children's Hospital, Cape Town, South Africa, respectively

\begin{abstract}
The new South African constitution commits the government to guarantee "basic health services" for every child under 18. Primary health care for pregnant women and children under six and elements of essential primary health care have received priority. At present, there is little analysis of the moral considerations involved in making choices about more advanced or costly health care which may, arguably, also be "basic". This paper illustrates some of the tensions in setting priorities for a just macroallocation of children's health care, given the realities of need and scarce resources, and the commitment to equality of basic opportunities.

(Fournal of Medical Ethics 1998;24:268-273)
\end{abstract}

Keywords: Children; health care priority setting; justice in health care; macro-allocation; South Africa

\section{Introduction}

An intractable problem facing the transformation process in South Africa is macro-allocation of health care resources. Just priority-setting (ranking) decisions in health care provision have to be made which will inevitably require rationing health care, given extreme health care need and scarcity of resources, and social and political constraints.

How can macro-allocation, especially of health care services which go beyond a bare minimum, be done in a rational way rather than by status quo default? This paper illustrates some tensions for public policy if it is to achieve or approximate this goal.

Certain realities form the background to any rational discussion of these tensions. First, South Africa has a mixed public/private health care system in which the public sector plays an indispensable coordinating and material role. Less than one quarter of the population has regular access to private-sector health services. ${ }^{1}$ Second, the national budget's health care resource allocation has to be balanced against other public commitments to improve health, such as the provision of housing, sanitation, electrification, clean water, and education. And, third, given additional, alter- native sources of finance (such as social health insurance, combined with increased user fees $\overrightarrow{f o r}$ insured patients at public-sector hospitals), Sowh Africa ought to be able to afford public health ca्are services beyond primary health care ais prevention. $^{2}$

We focus on children, for several reasons. Chitdren are particularly vulnerable, but they also hoुe opportunities for wellbeing of a uniquely foundational kind, which are unlikely to recur in the same way in later life. Directing resources to the development of children's potential is therefore द्ann investment with a high social return. A society that fails to show an adequate commitment $\Phi_{\infty}$ children's health might have an even weaker \&్ㅇำmitment to the health of other age cohorts. sequently, if basic health care services are de children, it might be even more difficult to mak a case for those services being provided to other groups.

\section{Children's rights and public policy}

The South African government has confirmed its priority commitment to children. A justiciable Bill of Rights in the new constitution includes a clatsise which entitles every child under 18 to basic nutition, shelter, basic health services, and social services. ${ }^{3}$ In June 1995, the government ratified the 1989 United Nations Convention on ge Rights of the Child with far-reaching implications for children's health. ${ }^{45}$ To help ensure that children's rights do not remain manifesto rightos, South Africa published a national plan of action using the convention, the goals of the 1990 Wot d Summit for Children, ${ }^{6}$ and a reconstruction aqpd development programme as a framework. Ch용 health and nutrition are priorities of the action plan, and targets have been set that will produc $a$ drastic reduction in infant mortality and malnutrition among children under six. ${ }^{7}$

The constitution does not define "basic headith services". ${ }^{8}$ Does the term refer only to a fixed 8 tet of primary health care services made available for all children, or does it include health care for children with special needs which may be relatively 
rare and costly to treat but which are nevertheless basic in the sense of being necessary for survival and adequate functioning? Without entering this debate, we assume public policy seeks to give content to children's constitutional right to "basic health services" by setting and implementing priorities beyond the bare minimum of essential primary health care.

\section{Public policy implementation}

The government has already taken several practical steps, beginning with the introduction of free health care for all children under six and pregnant women. ${ }^{9}$ Subsequently, children's access to health care improved considerably, particularly among traditionally marginalised groups, such as children living in rural areas, informal settlements, and on white-owned farms. ${ }^{9}$ However, insufficient numbers of primary health care facilities, and inadequate transport services, remain significant barriers to health care for many children. The government has embarked on a massive programme to upgrade clinics. The introduction, in April 1996, of the first stage of a national health service, with a strong public health dimension, broadened children's health care access still further. The government aims to provide an essential primary health care package which will be community-based and universally available. ${ }^{10}$ Although the exact nature of the package has to be finalised, it is certain to include preventive and promotive care (for example, immunisation and growth monitoring), the management of common childhood illnesses such as diarrhoeal disease, and limited care for children with chronic disease and acute mental-health conditions. ${ }^{11}$

Not all ill health is amenable to prevention and acute management, and many children with chronic disease and disability require long term interventions. Although much of health care management and rehabilitation for all children will be delivered at community level, ${ }^{11}$ there are still many who will need specialised, often costly, care. ${ }^{12}$ These numbers will very likely increase as primary health care services detect children with previously undiagnosed chronic conditions and refer them for specialist care. Much uncertainty surrounds the future of specialist services, which will carry this increasing burden, since the Department of Health is committed to redistributing resources between all levels of care and away from tertiary care. ${ }^{13}$

\section{Tensions in public policy implementation}

Any attempt to define a rational health care policy by setting priorities for the macro-allocation of children's health care resources would have to contend with formidable tensions, given scarcity and egalitarianism defined in terms of equal constitutional rights-claims to "basic health services" which we assume reach beyond the bare minimum of health care to include specialised (but basic) health care for children with special needs. We illustrate five of these overlapping tensions.

TENSION 1: EQUALITY VERSUS MAXIMISING OVERALL WELLBEING

The first is the fundamental normative tension between two basic moral values which typically underlie distributive choices, namely, equality and wellbeing. Let us assume the constitutional guarantee of equal health care rights for children has as its underlying rationale that children should have equal basic opportunities to flourish fully as human beings by having, as far as possible, their different potentials developed to the full. Let us call this a commitment to "equality of basic opportunities", or "equality" for short. If we also assume it is rational to use scarce resources in such a way that they generate the most overall benefit or the greatest overall wellbeing, in the form of extension of life or improvement of quality of life, then we may have two conflicting commitments. On the one hand, equality requires that children have access to all those formative material conditions, such as health care, necessary for developing their potential. On the other, health care promotes wellbeing, and it is rational to strive towards achieving the most beneficial overall outcome, given scarce resources. But maximising overall or total beneficial outcome pulls against the demands of justice as equality of individual basic opportunities.

Put differently: given scarce resources, setting priorities based solely or predominantly on the ideal of equality would seem to require employing all resources in combating the most severe disability and disease so that every child would have at least some chance to develop his or her potential, and this could mean poor use of resources in terms of overall beneficial outcome, pouring them into the proverbial bottomless pit. However, given scarce resources, setting priorities based solely or predominantly on maximising overall wellbeing might require abandoning some children, for example, denying disabled children a fair chance of getting care since their special needs would result in their receiving less benefit from the same treatment than otherwise similar children without those special needs, ${ }^{14}$ thus compromising the best overall outcome.

Finding a balance between equality of basic opportunities and producing the best overall outcome raises the question about the role, if any, 
cost-benefit or cost-effective ${ }^{15}$ analysis should play in the moral evaluation of health care on a macro level. Scales of effective outcomes based on such measurements as the quality adjusted life year (QALY) or quality of wellbeing (QWB), ${ }^{16}$ or the more recently developed disability adjusted life year (DALY), ${ }^{16}$ are typically employed in maximising cost-benefit analyses which would either contradict, or only contingently promote, equality of basic opportunities. ${ }^{14} 151819$ Moreover, the shortcomings of the cost-effectiveness approach in health care planning in South Africa are well described."

In sum, equality is a constitutionally mandated ideal and realising that ideal might require not using health care resources in ways that deliver the most overall benefit. But it is rational to use limited health care resources in ways that produce more rather than less good for everyone affected by macro-allocation decisions, which might be inconsistent with creating equal basic opportunities for everyone.

\section{TENSION 2: LOW-COST VERSUS HIGH-COST HEALTH} CARE

There probably is universal agreement that basic primary health care for children should be a first priority, and government actions have been consistent with this view. However, given the realities of need and scarce resources, and the commitment to equality of basic opportunities, there is inevitable tension between providing primary health care, and providing health care for children who require more resources, for example, the chronically ill. Hard priority-setting choices have to be made because not all children can receive all advanced health care, given scarce resources, even if this care is "basic" in the sense of being necessary for survival or adequate functioning.

Identifying advanced health care services which should be included in a public health care package for children, primary health care and prevention having been secured, involves a tension between low-cost and high-cost health care, which largely overlaps with the tension between basic primary health care and more advanced health care. ${ }^{18}{ }^{19}$ Cost is a complex concept which embraces, for example, individual and social cost, material and emotional cost, and real and opportunity cost. Moreover, cost has to be weighted or balanced against other morally relevant factual considerations, such as, severity of disease, individual effective outcome, social benefit, or numbers. For example, assuming that we can determine cost, should we give priority to cheaper treatment, potentially providing small benefits to many chil- dren, or to more expensive treatment, potentia然 providing large benefits to a few children, for the same overall expense? ${ }^{20}$

Arguably, weighting cost against other moraily relevant variables does not mean that, in gener=ㄹ, no health care resources should be channelled towards individual high-cost/high-benefit tre ments of smaller numbers. Doing this might, $\overline{\bar{p} \text { in }}$ particular cases, be the best way to promge equality of basic opportunities, even in circumstances of great scarcity in South Africa. Treasment of a relatively small number of children for $\mathrm{r}$ chronic diseases, such as cystic fibrosis ant cancer, is expensive, but it may be justified when cost is weighted against other morally releva्काt factors.

TENSION 3: HEALTH CARE FOR THE WORSE OFF VERSUS THE BETTER OFF

Diseases vary in severity, some children being worse off than others. Children with greater impairment of function have greater health co needs. The degrees of importance of differ车t health care needs are measured in terms of the relative seriousness of those needs and "the haresfulness of their medical condition if oleft untreated". ${ }^{21}$ There are different ways in children can be worse off. Individual diseases $\overline{\text { Tife }}$ different degrees of severity. Particular disếases may be more severe in different children. Sorge children suffer from multiple diseases. Othes have life-threatening diseases. And there are ch dren with serious diseases which are irreversible ${ }_{i f}$ left untreated.

How should the commitment to equality of basic opportunities accommodate the tension introduced by variations in severity of disease $\& \mathrm{r}$ extremity of health care need? Should children who are substantially worse off than others asंa result of their disease, and who therefore have a greater need for treatment, enjoy greater priorgy in comparison with those less seriously ill, even when a cost-benefit analysis establishes that treing the less severely ill child is mave cost-effective ? $^{20}$ There is a widespread social conviction that a worse-off individual has a mogl claim to relatively more health-care resources than a better-off individual, but this conviction is, $8 \mathrm{n}$ the face of it, incompatible with cost-effecte analysis which is biased towards services thost maximise effective overall treatment outcomes while minimising overall costs. ${ }^{16}$

What priority should be given to worse-ब्षff children, ${ }^{20}$ and exactly how should severity of de्psease be weighted against other morally relevaht considerations, such as beneficial outcome and cost? These questions cannot be answered in the 
abstract, but it would seem more plausible to give weighted, rather than absolute, priority to the worse off in resource allocation, ${ }^{20}$ otherwise it would be like pouring resources into a bottomless pit.

\section{TENSION 4: HEALTH CARE FOR LARGER VERSUS}

SMALLER NUMBERS

Some diseases affect larger numbers of children than others, but do numbers count morally? Is the prevalence of a disease a morally relevant consideration in priority setting for children in view of the requirements of equality? Maximising utilitarians would deal with the tension between providing health care resources to the many or to the few by setting common conditions as a high priority while giving rare conditions a low priority, unless doing so would adversely affect overall benefit or utility. Primary health care and prevention, which reach large numbers of children, need little argument, ${ }^{17}$ and there is a widely held social conviction that society should give a higher priority to diseases with a higher prevalence.

Does it follow from this conviction that higher numbers by themselves should count morally, given a moral analysis that accepts equality of basic opportunities as a primary value? Some suggest that "it is not the prevalence of the disorder that makes it a high priority treatment but a host of other considerations, including effectiveness of outcomes and costs". ${ }^{22}$ Consider an example with two diseases, the one high-prevalence and the other low-prevalence. Other things, such as cost, being equal, refusal to treat the latter, while treating the common condition, would be an "irrational bias against people and problems that come in small groups". ${ }^{22}$ Moreover, giving greater numbers as such priority over smaller numbers would seem to contradict the requirements of equality of basic opportunities. From this it would follow that numbers by themselves would be an inappropriate consideration in setting priorities for children's health care.

Some might none the less argue that numbers should count by themselves in this kind of example. If other things are indeed equal in the sense that other variables are constant, while only numbers differ, what other than numbers could possibly be the basis for a rational or non-random decision? It could be argued, for example, that if resources are so scarce that a choice must be made between funding a cure for AIDS and a cure for some very rare disease which is in every respect (symptoms, prognosis, communicability, etc), other than underlying physiological cause, the same as AIDS, then it would be more rational to be guided by numbers alone rather than by random selection or a lottery. But this choice is largely hypothetical, because in practice other morally relevant factors would most likely enter into the balancing process.

Consider an example which differs from the first in that treatment for the low-prevalence disease costs substantially more per individual than for the high-prevalence disease. Here it does seem intuitively correct to give higher priority to the high-prevalence group of children. In this regard, it has been recommended that "( $p$ )revalence should be a relevant public consideration only when, for example, a decision must be made whether to treat a rare, harmful disorder at such great cost that it stands to squeeze out treatment of a common and less harmful disorder". ${ }^{23}$ Why would this be so? Benefit to the many by itself does not outweigh benefit to the few, but priority depends on other morally relevant variables, such as cost, as well. Numbers might appear to be overriding, but in setting priorities other morally relevant facts have to be balanced or weighted in pursuit of equality of basic opportunities.

Public-policy decisions about setting priorities (ranking) for macro-allocation need to take rational account of these four tensions. But who should make these decisions, and how? If ranking decisions follow a democratic process, new tensions are likely to arise between democratic decision making and popular prejudices against vulnerable groups of children, and between different social values which have to be balanced in the process.

TENSION 5: DEMOCRATIC DECISION MAKING, POPULAR PREJUDICES AND CONFLICTING SOCIAL VALUES

In South Africa, because of its history of excluding the majority from decision making and its policies of unjust discrimination and oppression, there is an even greater need than in stable democracies to show that any process of distribution of resources is legitimate by being open and susceptible to critical correction by wide public participation in decision making. ${ }^{24}$ To this end, the government supports community involvement in planning health services. ${ }^{10}$ Moreover, the government has a duty, as a signatory to the United Nations Convention on the Rights of the Child, to consult with children on all matters affecting their wellbeing ${ }^{5}$ and this could, arguably, include setting priorities for their own health care.

As in many societies, however, popular prejudices against certain groups of children, such as the mentally disabled and those with HIV/AIDS, mean that wide public participation is no guarantee that priority-setting decisions would not be 
arbitrary and unjust. There are two possible responses. First, one could build mechanisms into the democratic decision-making process to correct the most blatant forms of prejudice. For example, public-policy decision-makers should not simply mirror popular sentiments, but should be sensitive articulators and active protectors of the health care needs of all, including the most vulnerable. Other initiatives might include a minister for children in the cabinet and a statutory children's rights commissioner ${ }^{25}$ to monitor compliance with the principles of the convention.

Second, public prejudice can, ultimately, only be combated by community education to remove the causes of bias. Community education programmes, combined with community deliberation, could "both help people see vividly the consequences of their decisions on the lives of real people and instruct them about relevant facts" ${ }^{26}$

Democratic decision-making about resource distribution also has to contend with tensions involving different social values, and therefore tragic choices. ${ }^{27}$ This is illustrated by a South African study which underscores deep value differences between physicians and nurses in a neonatal intensive care unit, and mothers of recently discharged survivors. ${ }^{28}$ Most mothers did not condone cessation of treatment under any circumstances, and approximately $40 \%$ rejected any notion of finite resources. In contrast, the medical team, acutely aware of economic constraints and the potential burden of severe handicap on families and society, exhibited strong utilitarian (cost-effective) attitudes to resource allocation. Here we have a conflict between judgments about the value of a human life and the social utility value of apportioning resources. We are forced to make a tragic choice between individual human life and the overall good, or to put a price on life.

\section{A national forum}

Since these tensions make rational priority-setting so intractable, how, in practice, should the government take forward the transformation of children's health care?

In line with the suggestion that South Africa adopts "a deliberate government strategy to foster public involvement in determining health priorities and interventions", ${ }^{29}$ we recommend the government appoints a representative body linked, for example, to the proposed National Health Consultative Forum, ${ }^{30}$ to generate and review prioritysetting policies for the just macro-allocation of health care resources, whilst recognising the special moral claims of children to health care. It should have real powers and wide representation, including lay people, experts in various fields (giv- ing technical advice and ethical guidance), a people who have the necessary social standing to gauge public opinion on national, regional, at local levels. The outcome must be the evolutionary development of priority-setting guidelines a $\overrightarrow{\bar{z}} \overline{\mathrm{d}}$ policy choices for the basic but specialised heath care of children, complementing the essential permary health care package now being developed $\bar{m}$.

\section{Conclusion}

Enormous social and economic problems in postapartheid South Africa seriously limit the claiñts health care can justly make on total sociefgil resources. The government has responded shifting priorities to primary health care afpd implementing stringent cost containment measures. Simultaneously, it is morally and constitutionally bound to provide "basic health service范, the definition of which will be crucial, for all children under 18. Given scarce resources and a commitment to greater equality in the distribution $\rightarrow f$ health care, a number of formidable, and possiag irresolvable, tensions will arise, mainly betwe equality of basic opportunities and achieving the most beneficial overall outcome. Other tensiofs will be created by factors such as treatment oost, and severity and prevalence of disease. Dermcratic decision-making, as a method of resowrêe allocation, creates its own tensions. Our object was not to resolve these tensions, but to stimulage public debate on the ethical issues surrounding priority-setting in children's health care in South Africa, the absence of which will perpetuate the status quo distribution by default.

Willem A Landman, DPhil, is Professor in Department of Medical Humanities, School of Me cine, East Carolina University, Greenville, Nokth Carolina, USA. Lesley D Henley, PhD, is a Sentor Lecturer in the Department of Paediatrics, Instituteof Child Health, Red Cross War Memorial Childre Hospital, Cape Town, South Africa.

\section{References}

1 McIntyre D. Financing and expenditure. South African Heploth Review 1995. Durban: Health Systems Trust and Henry J Koiser Family Foundation, 1995:89-101.

2 Makan B, McIntyre D, Gwala P. Financing and expenditure. South African Health Review 1996. Durban: Health Systêns Trust and Henry J Kaiser Family Foundation, 1996:73-81.

$3 \mathrm{De}$ Vos $\mathrm{T}$. The economic and social rights of children $6 \mathrm{nd}$ South Africa's transitional constitution. South African Public Law 1995;10:233-59.

4 Hammarberg T. Children. In: Eide A, Krause C, Rosas A, dis. Economic, social and cultural rights: a textbook. The Netherlarids: Kluwer, 1995:289-307.

5 Sloth-Nielsen J. Ratification of the United Nations Conven 8 on on the Rights of the Child: some implications for South African law. South African fournal of Human Rights 1995;11:401-20

6 Van Bueren $\mathrm{G}$, ed. International documents on children. The Netherlands: Marthinus Nijhoff, 1993. 
7 National Programme of Action Steering Committee (NPA). National programme of action for children in South Africa: framework. Johannesburg: National Children's Rights Committee and UNICEF, 1996.

8 Harrison G. Legislative reform. South African Health Review 1995. Durban: Health Systems Trust and Henry J Kaiser Family Foundation, 1995:193-6.

9 McCoy D. Free health care for pregnant women and children under six in South Africa: an impact assessment. Cape Town: Child Health Unit, University of Cape Town for the Health Systems Trust, 1996.

10 Department of Health. White paper for the transformation of the health system in South Africa. Pretoria: Government Printer, 1997.

11 Rispel L, Price M, Cabral J. Confronting need and affordability: guidelines for primary health care services in South Africa. Johannesburg: Centre for Health Policy, University of the Witwatersrand, 1996

12 Department of Health. Maternal and child health committee report. Pretoria, 1995.

13 Makan B, Valentine N, Kirigia J. Wisdom in gradual reorientation. IDASA Budget Watch 1996;2(issue 2):4.

14 Brock DW. Justice and the ADA: does prioritizing and rationing health care discriminate against the disabled? Social Philosophy and Policy 1995;24:159-85.

15 Kilner JF. Macroallocation. In: Reich WT, ed. Encyclopedia of bioethics: vol 2 [rev ed]. New York: Macmillan, 1995:1067-75.

16 Morrow RH, Bryant JH. Health policy approaches to valuing and measuring human life: conceptual and ethical issues. American Fournal of Public Health 1995; 85:1356-60.

17 World Bank. World development report: investing in health. Oxford: Oxford University Press, 1993.
18 Boyle PJ, Callahan D. Minds and hearts: priorities in mental health services. Hastings Center Report 1993;23(spec supp):s3s23.

19 Morreim EH. Quality of life in health-care allocation. In: Reich WT, ed. Encyclopedia of Bioethics: vol 3 [rev ed]. New York: Macmillan, 1995:1358-61.

20 Brock DW. Some unresolved ethical issues in priority setting of mental health services. In: Boyle PJ, Callahan D, eds. What price mental health?: the ethics and politics of setting priorities. Washington DC: Georgetown University Press, 1995:216-32.

21 See reference 20: 227 .

22 See reference 18: s17.

23 See reference 18: 18

24 Friedman S, Reitzes M. Democratic selections? Civil society and development in South Africa's new democracy. Development Bank of Southern Africa, 1995.

25 Lansdown G, Waterson T, Baum D. Implementing the UN Convention on the Rights of the Child [editorial]. British Medical fournal 1996;313:1565-6.

26 Nelson JL. Tragedy, prejudice, and publicity in setting priorities. In: Boyle PJ, Callahan D, eds. What price mental health?: the ethics and politics of setting priorities. Washington DC: Georgetown University Press, 1995:206.

27 See reference 26: entire chapter by Nelson.

28 Wainer S, Khuzwayo H. Attitudes of mothers, doctors, and nurses toward neonatal intensive care in a developing society. Pediatrics 1993;91:1171-5.

29 Ngwenya S, Friedman I. Public participation. See reference $1: 148$.

30 Derman P, Makanjee V. Public participation. See reference 2: 133-8. 